\title{
Потребление сердечно-сосудистых
}

и антитромботических препаратов в период распространения коронавирусной инфекции в розничном секторе фармацевтического рынка Самарской области

\author{
И.К. Петрухина, П.А. Лебедев ${ }^{\bowtie}$, Т.К. Рязанова, П.Р. Блинкова, Е.В. Паранина \\ ФГБОУ ВО «Самарский государственный медицинский университет» Минздрава России, Самара, Россия
}

\begin{abstract}
Аннотация
Цель. Изучение многолетней статистики продаж в сегменте аптечного рынка для оценки объема и структуры потребляемых сердечно-сосудистых и антитромботических препаратов в условиях пандемии COVID-19.

Материал и методы. Сведения о номенклатуре и объемах отпуска препаратов аптечного сегмента Самарской области в 2015-2020 гг. Результаты. Показано, что доля основных сердечно-сосудистых препаратов в натуральном выражении незначительна (5,2-3\%). Наибольший объем продаж составляют препараты группы ингибиторов ангиотензинпревращающего фермента (28\%) и $\beta$-адреноблокаторов (23,5\%). Фиксированные комбинации гипотензивных препаратов составляют лишь 13\% объема реализованных основных сердечно-сосудистых препаратов, а доля статинов - 7,6\%, что не соответствует их роли как наиболее эффективных препаратов в первичной и вторичной кардиопревенции. Доля антитромботических препаратов в общем объеме продаж в натуральном выражении в 2015-2019 гг. составляла 0,45\%. В абсолютном выражении продажи антикоагулянтов и дезагрегантов возросли в 2018-2020 гг., что сопровождалось увеличением стоимости суточной дозы в среднем на $15 \%$. Среди дезагрегантов наиболее часто реализуется ацетилсалициловая кислота (66,6\%), клопидогрел $(21,6 \%)$, дипиридамол (10,2\%). Доля дезагрегантов в объемах продаж снизилась с 74,8 до 57,6\% за счет препаратов ацетилсалициловой кислоты. В 2020 г. значительно выросло потребление дипиридамола до 16,6\% в связи с включением препарата в протоколы ведения пациентов c COVID-19. Среди антикоагулянтов доля новых оральных препаратов характеризуется поступательным увеличением с 7,8\% в 2015 г. до 27\% в 2020 г. В период пандемии COVID-19 наиболее востребованной является группа блокаторов Ха фактора с преобладанием апиксабана (63,8\%), что может объясняться более низкой стоимостью (на 16\%) суточной эквивалентной дозы в сравнении с ривароксабаном.

Заключение. Отмечено низкое потребление основных сердечно-сосудистых препаратов среди населения Самарской области, особенно статинов и комбинированных гипотензивных препаратов. В период пандемии COVID-19 произошло увеличение потребления антитромботических препаратов за счет дипиридамола и новых пероральных антикоагулянтов.
\end{abstract}

Ключевые слова: лекарственное обеспечение населения, препараты для лечения сердечно-сосудистых заболеваний, антитромботические препараты, COVID-19

Для цитирования: Петрухина И.К., Лебедев П.А., Рязанова Т.К., Блинкова П.Р., Паранина Е.В. Потребление сердечно-сосудистых и антитромботических препаратов в период распространения коронавирусной инфекции в розничном секторе фармацевтического рынка Самарской области. CardioСоматика. 2021;12(4):219-226. DOI: 10.17816/22217185.2021.4.201282

\section{Введение}

Фармакотерапия сердечно-сосудистых заболеваний является эффективной стратегией снижения ассоциированной инвалидности и смертности и рассматривается в качестве основного направления борьбы с неинфекционными заболеваниями. Особенность современного этапа заключается в сочетании двух пандемий - инфекционной, обусловленной распространением COVID-19, и пандемией сердечно-сосудистых заболеваний, которая продолжает наносить основной ущерб популяции Российской Федерации. Известно, что сердечно-сосудистая коморбидность является детерминантой тяжелого течения и смертности у пациентов с COVID-19 [1].
Вирус SARS-CoV-2, обладая высокой тропностью к сосудистому эндотелию, усугубляет его дисфункцию, пропорциональную сердечно-сосудистому риску, тем самым создавая основу для артериальных и венозных тромбозов, дестабилизации существующих атеросклеротических бляшек [2,3].

В сложившейся ситуации купирование основных факторов сердечно-сосудистого риска: артериальной гипертензии (АГ), гиперхолестеринемии и дислипидемии наряду с фармакотерапией заболеваний, обусловленных атеросклерозом, приобретает как никогда острую медико-социальную значимость $[4,5]$.

В условиях пандемии COVID-19 весьма затруднительны традиционные подходы, использующиеся в крупных эпидемио-
СПИСОК СОКРАЩЕНИЙ

АГ - артериальная гипертензия

ACK - ацетилсалициловая кислота

ATX - анатомо-терапевтически-химический

БКК - блокаторы кальциевых каналов

БРА - блокаторы рецепторов ангиотензина II

БСК - болезни системы кровообращения

ГХТ - гидрохлоротиазид

ИАПФ - ингибиторы ангиотензинпревращающего фермента
ЛП - лекарственный препарат

МНH - международное непатентованное наименование

ООР - общий объем реализации

ССП - сердечно-сосудистый препарат

ФК - фиксированная комбинация

DDD (defined daily dose) - средняя суточная поддерживающая доза 


\title{
Consumption of cardiovascular and antithrombotic drugs during the spread of coronavirus infection in retail sector of the Samara region pharmaceutical market
}

\author{
Irina K. Petrukhina, Petr A. Lebedev ${ }^{凶}$, Tatyana K. Ryazanova, Polina R. Blinkova, Elena V. Paranina \\ Samara State Medical University, Samara, Russia
}

\begin{abstract}
Aim. Study of multi-year sales statistics in pharmacy market segment to assess the volume and structure of consumed cardiovascular and antithrombotic drugs under COVID-19 pandemic conditions.

Material and methods. Data on nomenclature and sales volumes of drugs in pharmacy segment of Samara region in 2015-2020.

Results. It is shown that the share of basic cardiovascular drugs in physical terms is insignificant (5.2-3\%). Thelargest volume of sales are drugs of angiotensin-converting enzyme inhibitor group (28\%) and $\beta$-adrenoblockers $(23.5 \%)$. Fixed combinations of hypotensive drugs account for only $13 \%$ of the volume of sold basic cardiovascular drugs, and the share of statins is $7.6 \%$, which does not correspond to their role as the most effective drugs in primary and secondary cardiac prevention. The share of antithrombotic drugs in total sales in volume terms was $0.45 \%$ in $2015-2019$. In absolute terms, sales of anticoagulants and disaggregants increased in 2018-2020, which was accompanied by an average $15 \%$ increase in the cost per daily dose. Among disaggregants, acetylsalicylic acid (66.6\%), clopidogrel (21.6\%), and dipyridamole $(10.2 \%)$ are most frequently sold. The share of disaggregants in sales fell from 74.8 to $57.6 \%$ at the expense of acetylsalicylic acid drugs. In 2020 , consumption of dipyridamole increased significantly to $16.6 \%$ due to inclusion of the drug in protocols for managing patients with COVID-19. Among anticoagulants, the proportion of new oral medications is characterized by a progressive increase from $7.8 \%$ in 2015 to $27 \%$ in 2020. During the COVID-19 pandemic, the most demanded group of Xa factor blockers is dominated by apixaban (63.8\%), which can be explained by thelower cost (by 16\%) of a daily equivalent dose compared to rivaroxaban.

Conclusion. Low consumption of basic cardiovascular drugs among the population of Samara region, especially statins and combined hypotensive drugs was observed. During COVID-19 pandemic there was an increase in consumption of antithrombotic drugs, due to dipyridamole and new oral anticoagulants.
\end{abstract}

Keywords: medication supply, cardiovascular drugs, antitrombotic drugs, COVID-19

For citation: Petrukhina IK, Lebedev PA, Ryazanova TK, Blinkova PR, Paranina EV. Consumption of cardiovascular and antithrombotic drugs during the spread of coronavirus infection in retail sector of the Samara region pharmaceutical market. Cardiosomatics. 2021;12(4):219-226. DOI: 10.17816/22217185.2021.4.201282

логических исследованиях, посвященных изучению профиля используемых в реальной клинической практике препаратов, их соответствия утвержденным рекомендациям, как, например, в программах «Пифагор» и ЭССЕ РФ [6]. Потребление лекарственных препаратов (ЛП), реализуемых через аптечную сеть за счет собственных средств населения, в денежном выражении составляет 64 и 85\% - в упаковках от общего объема [7]. Использование фармакоэпидемиологического подхода - изучения статистики продаж препаратов, реализуемых населению через аптечную сеть, - позволяет оценить объемы и структуру потребляемых препаратов в популяции, изучить динамику спроca, с тем чтобы управлять ими в дальнейшем. С этой целью нами предпринято исследование потребления основных сердечно-сосудистых средств в виде монопрепаратов и фиксированных комбинаций (ФК), а также антитромботических средств в аптечном сегменте Самарской области.

\section{Материал и методы}

Материалом исследования являлись сведения о номенклатуре и объемах отпуска препаратов за 2015-2020 гг. «Дежурная аптека 245», относящихся к сердечно-сосудистым: ингибиторы ангиотензинпревращающего фермента (ИАПФ), блокаторы рецепторов ангиотензина II 1-го типа (БРА), блокаторы кальциевых каналов (БКК), $\beta$-адреноблокаторы, диуретики, селективные блокаторы $\alpha$-рецепторов и агонисты имидазолиновых рецепторов, а также их ФК. Антитромботические препараты проанализированы в разрезе подгрупп по анатомо-терапевтически-химической (ATX) классификации: В01АA «Антагонисты витамина К», В01AB «Гепарин и его производные», B01AC «Ингибиторы агрегации тромбоцитов (исключая гепарин)», B01AE «Прямые ингибиторы тромбина», B01AF «Прямые ингибиторы фактора Ха» и B01AX «Прочие антикоагулянты».

Статистическую обработку числового материала проводили с использованием статистического программного пакета IBM SPSS Advanced Statistics 24.0 №5725-A54 (IBM, США). Проверка нормальности распределения количественных признаков в группах проводилась с использованием критерия Шапиро-Уилка. Для всех количественных признаков производилась оценка средних арифметических и медианы. Дескриптивные статистики в тексте представлены как $M \pm S D$, где M - среднее арифметическое, SD - стандартное отклонение, или Med (в случае, если выборка не подчинялась закону нормального распределения).

Оценка репрезентативности выборки в проводимых исследованиях осуществлялась по оценке количества покупок антикоагулянтных и антиагрегантных ЛП. С этой целью использована формула

$$
\mathrm{m}=2 \sqrt{ } \mathrm{n},
$$

где $\mathrm{m}$ - полученная численность выборки, n - численность генеральной совокупности.

Под генеральной совокупностью в проводимых исследованиях понимается численность населения Самарской области 


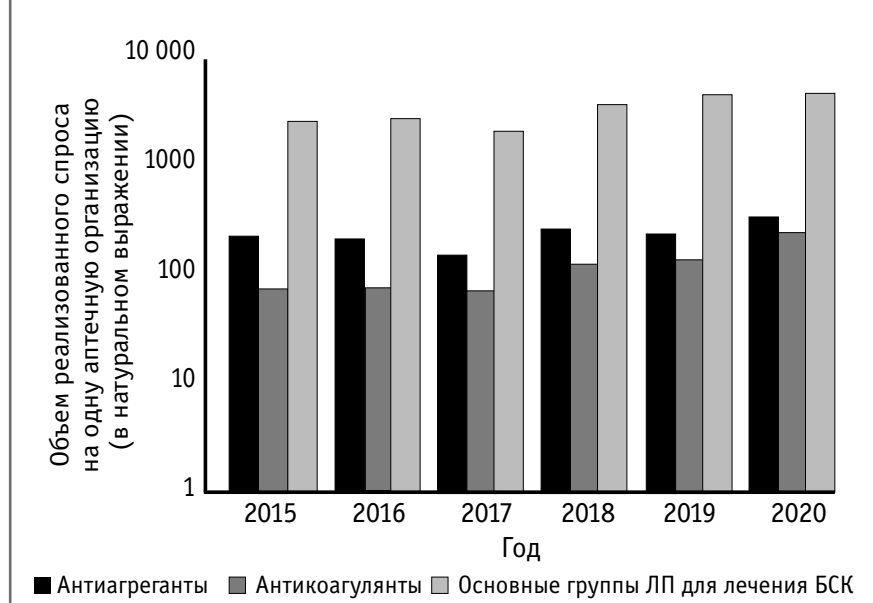

Рис. 1. 0бъем реализованного спроса в упаковках в 2015-2020 гг. препаратов для лечения БСК, антикоагулянтов и дезагрегантов на одну аптечную организацию.

Fig. 1. The volume of sold cardiovascular drugs, anticoagulants and disaggregants in packages per pharmacy organization in 2015-2020.

(n в 2020 г. составляет 3179000 человек). Следовательно, численность выборки для обеспечения ее репрезентативности должна составлять 3566 покупок ЛП в 2020 г. В 2015-2020 гг. в исследуемой сети ежегодно совершалось более 5,5 тыс. покупок, что подтверждает репрезентативность полученных данных, т.е. соответствие характеристик выборки характеристикам генеральной совокупности.

Для препаратов рассчитывали стоимость одной средней суточной поддерживающей дозы (defined daily dose - DDD) путем деления общей стоимости упаковок препаратов с одним международным непатентованным наименованием (МHH) на общее количество DDD.

\section{Результаты}

1. Структура реализованного спроса на основные сердечно-сосудистые препараты (ССП). В настоящее время фарминдустрия предоставляет разнообразный спектр препаратов для лечения болезней системы кровообращения (БСК) различного механизма действия, в том числе наделенных плейотропными свойствами, не только в виде монопрепаратов, но и в виде ФК, обеспечивая врача разнообразным инструментарием. Хотя большинство исследуемых препаратов относится к гипотензивным средствам, сфера их применения гораздо шире и включает хроническую сердечную недостаточность ( $\beta$-адреноблокаторы, ИАПФ/БРА, диуретики), ишемическую болезнь сердца (БКК, $\beta$-адреноблокаторы, статины). Доля в реализованных упаковках этих препаратов в общем объеме продаж составила от 5,2 до 5,8\% в 2015-2017 гг. и уменьшилась до 2,7\% в 2018 г., до 3,2\% в 2019 г. и до 3\% - в 2020 г. В абсолютных цифрах реализованных упаковок на одну аптечную организацию с 2018 г. отмечен слабый прирост (рис. 1). Тем не менее востребованность этой группы препаратов населением представляется низкой.

При изучении структуры потребления среди основных препаратов для лечения БСК выявлено, что 1-е место от общего объема реализации (00Р) как монопрепараты составляют ИАПФ 28,0\% (рис. 2). Внутри этой группы по объемам потребления в натуральном выражении преобладали ЛП эналаприла (58,7\%) и каптоприла (19,8\%). Современные представители этой группы - лизиноприл $(6,1 \%)$ и периндоприл $(9,8 \%)$ - пользуются существенно меньшим спросом. Из этой группы эналаприл и
Трехкомпонентные ФК и более $\square 0,7$

БКК + статин 0,0

БКК + диуретик 0,1

ß-Адреноблокатор + БКК $\square 1,4$

$\beta$-Адреноблокаторы + диуретик $\square 0,4$ БРА + БКК $\square 1,4$

БРА + диуретик 4,0

ИАПФ + БКК $\square 1,9$

ИАПФ + диуретик 3,8

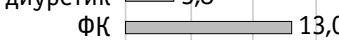

Статины $\square 7,9$

及-Адреноблокаторы $\longleftarrow 23,5$

БКК

БРА $\square 7,2$

ИАПФ$$
2
$$

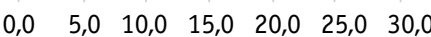

Рис. 2. Средние доли объема реализованного спроса монопрепаратов и комбинированных ЛП разных фармакотерапевтических групп, применяемых для лечения гипертонической болезни в 2015-2020 гг.

Fig. 2. Average shares of sales volume of monodrugs and combined drugs of different pharmacotherapeutic groups used for the treatment of hypertension in 2015-2020.

каптоприл реализуются как монопрепараты в 93,5 и 98,7\% случаев, лизиноприл - в 83,6\%, периндоприл - в 39,4\%. Доля оригинальных препаратов в этой группе составляет $20 \%$.

В структуре потребления монопрепаратов $\beta$-адреноблокаторы статистически недостоверно уступают ИАПФ - 23,5\% от 00Р. Среди этой группы наибольшие объемы потребления в натуральном выражении имели препараты бисопролола (69,4\%) и метопролола (11,7\%). Фактически подавляющее большинство $\beta$-адреноблокаторов реализуется как монопрепараты. Их доля составляет 92,7\%. Доля оригинальных препаратов - 41,9\%.

БКК в доле 00Р занимают 3-е место $(10,2 \%)$ с тенденцией к снижению (11,1-9,3\%). Наибольший объем продаж в этой группе обеспечивает амлодипин - 64,6\%, затем нифедипин - 22,4\%, оба представители дигидропиридиновых производных. На долю препаратов нифедипина короткого действия в среднем приходилось $20 \%$ общего объема потребления препаратов нифедипина.

БРА - перспективная, бурно развивающаяся группа гипотензивных препаратов [6] - в изученном секторе розничной сети Самарской области занимает 4-е место по 00Р (7,2\%) с четкой тенденцией к росту $(5,8-8,7 \%)$. Самым продаваемым является препарат лозартан (52,8\%), валсартан с большим отрывом занимает 2-е место (18,0\%). Доля современных препаратов (кандесартана - 9,1\%, телмисартана - 8,2\%, азилсартана - 8,5\%) незначительна, но для двух последних имеет выраженную тенденцию к росту (3,9-12,36\%).

На долю тиазидовых диуретиков приходится 5,8\% 00Р, из них индапамид как монопрепарат обеспечивает 75,3\% продаж в этой группе, а гидрохлоротиазид (ГХТ) - 25\%. В нашем анализе диуретики явились компонентами $23 \mathrm{MHH} \mathrm{ФК,} \mathrm{в} \mathrm{которых} \mathrm{наи-}$ более часто использовался ГХТ - исторически один из первых представителей данной группы.

Средняя доля комбинированных препаратов в общей структуре отпущенных упаковок в 2015-2020 гг. составила 13\%. Ассортимент ЛП, назначаемых для лечения АГ, увеличился С 78 МНH в 2015 г. до 88 МНH в 2020 г., главным образом за счет ФК. Комбинированными препаратами с наибольшими объемами отпущенных упаковок были периндоприл + индапамид - 2,12\% общего объема отпущенных упаковок; лозартан + ГХТ - 2,05\%, амлодипин + периндоприл - 1,45\%, эналаприл + ГХТ - 0,94\%, 
Таблица 1. Структура потребления антикоагулянтных и антиагрегантных ЛП в розничном сегменте фармацевтического рынка Самарской области Table 1. Consumption structure of anticoagulant and antiplatelet drugs in the retail segment of the Samara region pharmaceutical market

\begin{tabular}{|c|c|c|c|c|c|c|c|}
\hline \multirow{3}{*}{$\begin{array}{l}\text { ATХ-группа антикоагулянтных } \\
\text { и антиагрегантных ЛП. МНН* }\end{array}$} & \multicolumn{7}{|c|}{ Доля объема реализованного спроса (в упаковках), \%** } \\
\hline & \multicolumn{6}{|c|}{ данные для отдельных лет } & \multirow{2}{*}{$\begin{array}{l}\text { стандартное } \\
\text { отклонение [SD] } \\
\text { в 2015-2020 гг. }\end{array}$} \\
\hline & 2015 г. & 2016 г. & 2017 г. & 2018 г. & 2019 г. & 2020 г. & \\
\hline В01АА «Антагонисты витамина K» & 7,5 & 6,7 & 7,5 & 6,0 & 6,1 & 4,9 & $6,5(1,0)$ \\
\hline Фениндион & 22,9 & 4,3 & 8,1 & 4,8 & 7,8 & 8,3 & $9,4[6,8)$ \\
\hline Варфарин & 77,1 & 95,7 & 91,9 & 93,8 & 92,1 & 91,7 & $90,4(6,7)$ \\
\hline Аценокумарол & 0,0 & 0,0 & 0,0 & 1,4 & 0,2 & 0,0 & $0,3(0,6)$ \\
\hline В01АВ «Гепарин и его производные» & 18,8 & 16,1 & 19,1 & 24,2 & 23,1 & 16,9 & $19,7(3,3)$ \\
\hline Гепарин натрия & 4,8 & 6,3 & 4,1 & 3,1 & 2,0 & 8,7 & $4,8(2,4)$ \\
\hline Далтепарин натрия & 0,0 & 0,0 & 0,0 & 0,0 & 0,0 & 0,6 & $0,1(0,2)$ \\
\hline Эноксапарин натрия & 23,3 & 18,1 & 17,7 & 19,8 & 14,5 & 25,3 & $19,8(3,9)$ \\
\hline Надропарин кальция & 6,5 & 5,3 & 3,6 & 4,0 & 6,3 & 5,4 & $5,2(1,2)$ \\
\hline Парнапарин натрия & 0,0 & 0,0 & 0,0 & 0,0 & 0,9 & 8,1 & $1,5(3,2)$ \\
\hline Сулодексид & 18,4 & 26,8 & 25,6 & 29,6 & 29,9 & 13,9 & $24,0[6,5]$ \\
\hline $\begin{array}{l}\text { В01АС «Ингибиторы агрегации тромбоцитов } \\
\text { (исключая гепарин)» }\end{array}$ & 74,8 & 72,8 & 70,1 & 67,2 & 63,7 & 57,6 & $67,7(6,3)$ \\
\hline Клопидогрел & 18,0 & 19,9 & 19,4 & 24,5 & 28,5 & 19,1 & $21,6(4,1)$ \\
\hline ACK & 71,7 & 71,5 & 71,4 & 62,7 & 61,2 & 61,6 & $66,7(5,4)$ \\
\hline Дипиридамол & 9,0 & 7,7 & 8,4 & 12,1 & 7,5 & 16,7 & $10,2(3,6)$ \\
\hline Илопрост & 0,8 & 0,4 & 0,4 & 0,0 & 0,0 & 0,0 & $0,3(0,3)$ \\
\hline Прасугрел & 0,0 & 0,0 & 0,0 & 0,0 & 0,1 & 0,4 & $0,1(0,2)$ \\
\hline Цилостазол & 0,0 & 0,0 & 0,0 & 0,0 & 1,3 & 1,2 & $0,4(0,7)$ \\
\hline Тикагрелор & 0,5 & 0,5 & 0,5 & 0,8 & 1,4 & 1,1 & $0,8(0,4)$ \\
\hline В01АЕ «Прямые ингибиторы тромбина» & 2,6 & 3,5 & 3,8 & 2,5 & 3,2 & 3,0 & $3,1(0,5)$ \\
\hline Дабигатрана этексилат & \multicolumn{7}{|c|}{ Единственный представитель группы } \\
\hline B01АF «Прямые ингибиторы фактора Ха» & 5,2 & 7,9 & 8,8 & 10,5 & 14,7 & 24,0 & $11,9[6,7]$ \\
\hline Ривароксабан & 81,9 & 59,4 & 53,4 & 50,8 & 40,9 & 36,2 & $53,8(16,2)$ \\
\hline Апиксабан & 18,1 & 40,6 & 46,6 & 49,2 & 59,1 & 63,8 & $46,2(16,2)$ \\
\hline B01AХ «Прочие антикоагулянты» & 0,0 & 0,0 & 0,0 & 0,0 & 0,0 & 0,0 & $0,01(0,01)$ \\
\hline Фондапаринукс натрия & 0,0 & 100,0 & 0,0 & 0,0 & 0,0 & 100,0 & $\mathrm{H} / \Pi$ \\
\hline \multicolumn{8}{|c|}{$\begin{array}{l}\text { Примечание: н/п - неприменимо. } \\
\text { ×Представлены МНН с наибольшими объемами реализованного спроса внутри каждой фармакотерапевтической группы. } \\
\text { *^Для анализа использованы показатели реализованного спроса в упаковках. Для фармакотерапевтических групп указаны доли общего объема реализо- } \\
\text { ванного спроса, для МНН - доля объема реализованного спроса для конкретной фармакотерапевтической группы. }\end{array}$} \\
\hline
\end{tabular}

азилсартан + хлорталидон - 0,66\%, амлодипин + индапамид + периндоприл $-0,47 \%$.

Доля статинов в объеме реализации ССП составила лишь $7,6 \%$, что никак не соответствует той роли, которую статинам отводит современная кардиопревенция. Аторвастатин в обновленном рейтинге ЛП в 2020 г. в США занимает 1-е место (110 млн выписанных рецептов), розувастатин - 29-е место (24 млн рецептов) [8]. В нашем исследовании в $98 \%$ статины продавались как монопрепараты, одинаково часто были востребованы аторвастатин $(46 \%)$ и розувастатин $(44 \%)$.

Тенденции последних лет заключаются в расширенном применении ФК как наиболее эффективных для коррекции артериального давления и в использовании статинов - плейотропных препаратов с основным холестеринснижающим действием у пациентов с высоким риском сердечно-сосудистых осложнений независимо от наличия АГ. Актуальность такого подхода обоснована значительным вкладом АГ и гиперхолестеринемии в развитие инфарктов миокарда и инсультов - основных причин смертности в РФ и мире [9] и связанных с ними социальными и экономическими потерями. Достаточно сказать, что распространенность АГ в РФ среди взрослого населения составляет не менее $45 \%$ и требует у большинства пациентов долговременного приема препаратов. Жесткий подход к контролю артериального давления стал лейтмотивом современных клинических рекомендаций [10], что несомненно значительно увеличивает потребность в использовании ФК уже на старте терапии. 


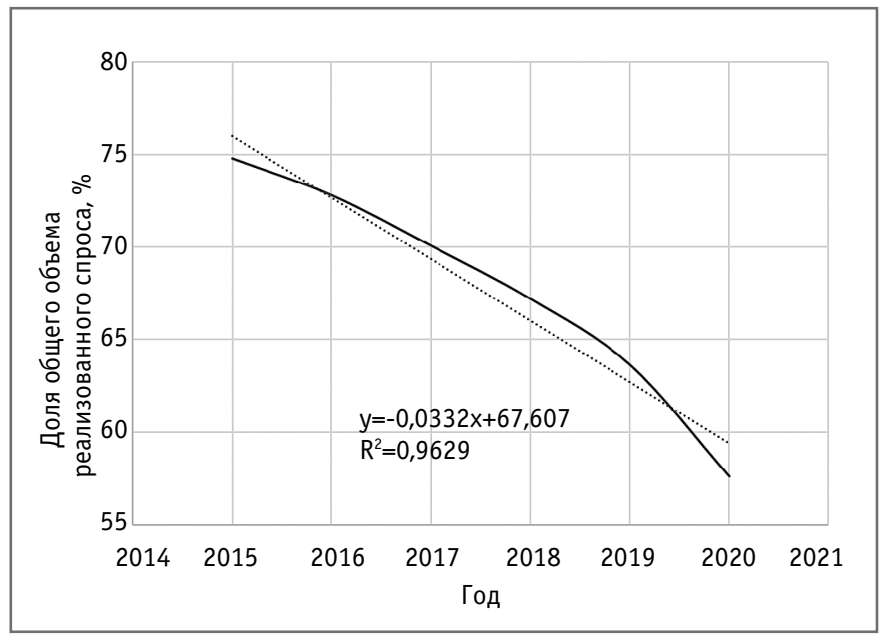

Рис. 3. Динамика доли ЛП АТХ-подгруппы В01АС в общем объеме потребления антитромботических ЛП в розничном сегменте фармацевтического рынка Самарской области в 2015-2020 гг.

Fig. 3. Dynamics of the share of B01AC anatomical therapeutic chemical subgroup drugs in the total consumption of antithrombotic drugs in the retail segment of the Samara region pharmaceutical market in 2015-2020.

2. Потребление антитромботических препаратов. В 2015-2019 гг. в розничном секторе фармацевтического рынка Самарской области доля антикоагулянтных и антиагрегантных ЛП в общей структуре отпущенных упаковок в среднем составила $0,45 \%$, т.е. примерно в 10 раз меньше, чем препаратов для лечения БСК: 0,59\% в 2015 г., 0,58\% - в 2016 г., 0,59\% - в 2017 г., 0,27\% - в 2018 г. и 0,28\% - в 2019 г.). По итогам 2020 г. этот параметр составил 0,38\%. Вместе с тем в абсолютном выражении продажи антикоагулянтов и дезагрегантов возросли в 2018-2020 гг. (см. рис. 1).

В течение всего временного промежутка максимальная доля общего объема реализованного спроса антитромботических ЛП приходится на АТХ-подгруппу B01AC «Ингибиторы агрегации тромбоцитов» (табл. 1, рис. 3). Прирост потребления антикоагулянтов, наблюдаемый с 2018 г. (см. рис. 1), стал особенно явным в 2020 г., благодаря ему превалирование продаж дезагрегантов уменьшилось с 74,8\% в 2015 г. до 57,6\% в 2020 г. (рис. 3).

В 2020 г. по сравнению с 2015-2019 гг. ассортимент ЛП рассматриваемой группы практически не изменился. В этом периоде в ассортименте исследуемой аптечной сети было представлено от 13 до 17 МНH и группировочных наименований, относящихся к антикоагулянтным и антиагрегантным ЛП (см. табл. 1).

В 2020 г., как и в предшествующие годы (2015-2019 гг.), в группе B01AC «Ингибиторы агрегации тромбоцитов (исключая гепарин)» наибольшие объемы потребления в натуральном выражении приходились на препараты ацетилсалициловой кислоты (АСК) и клопидогрела: 66,7 и 21,6\% соответственно. Доли потребления новых дезагрегантов - прасугрела и тикагрелора незначительны. В то же время отмечено существенное увеличение относительной доли препаратов, содержащих дипиридамол (с 7,5\% в 2019 г. до 16,7\% в 2020 г.).

Интерес к этому, фактически забытому в кардиологии, пероральному препарату связан с редким сочетанием свойств, потенциально полезных в лечении пациентов с COVID-19. Если дезагрегантные свойства препарата и способность снижать сосудистый тонус хорошо известны, то наличие противовирусных эффектов дипиридамола никогда ранее не привлекало внимание клиницистов. Механизм действия основан на ингибировании аденозиндезаминазы, в результате чего блокируется распад

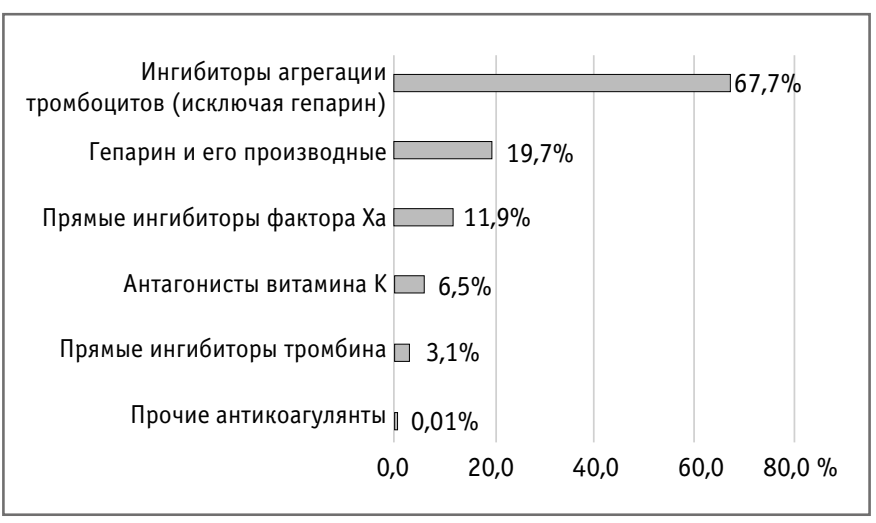

Рис. 4. Средние доли объема реализованного спроса антикоагулянтных и антиагрегантных ЛП в 2015-2020 гг. Fig. 4. Average shares of sales volume of anticoagulant and antiaggregant drugs in 2015-2020.

аденозина. Образование циклического аденозинмонофосфата снижает адгезию тромбоцитов с падением тонуса артериол. Эти эффекты лежат в основе хорошо известных показаний к препарату, как, например, лечение и профилактика нарушений мозгового кровообращения по ишемическому типу, дисциркуляторная энцефалопатия, профилактика артериальных и венозных тромбозов и их осложнений. Другими зарегистрированными в РФ показаниями к дипиридамолу являются профилактика и лечение гриппа, острых респираторных вирусных инфекций [11]. Являясь производным пиримидина, препарат способен подавлять синтез РНК вируса за счет ингибирования использования нуклеозидов. В качестве индуктора интерферона и иммуномодулятора дипиридамол в ряде исследований показал у инфицированных пациентов усиление противовирусного иммунного ответа [12]. Однако подтверждений клинической эффективности у пациентов с COVID-19, оправдывающих повышение спроса на препарат, на данный момент нет.

На 2-м месте в структуре потребления антикоагулянтов и антиагрегантов в натуральном выражении находятся ЛП ATX-подгруппы В01AB «Гепарин и его производные» [SD - 19,7\% (3,3\%)]; см. табл. 1 и рис. 4. Несмотря на то, что в 2015-2020 гг. доля ЛП этой ATX-подгруппы в общем объеме потребления оставалась достаточно стабильной, в натуральных показателях отмечено увеличение объемов отпуска препаратов гепарина и его производных (на 68\%). При этом наибольший рост числа реализованных упаковок выявлен для ЛП, содержащих гепарин натрия (в 5,9 раза по сравнению с данными для 2019 г. и в 4,6 раза по сравнению со средним значением объема отпуска в 2015-2019 гг.) и эноксапарин натрия (в 2,4 и 2,6 раза соответственно).

В 2020 г. отмечено существенное увеличение спроса на ЛП, относящиеся к новым оральным антикоагулянтам. Доля реализации совокупно дабигатрана, апиксабана и ривароксабана поступательно увеличивалась с 7,75\% в 2015 г., 11,5\% в 2016 г., 12,7\% в 2017 г., 13,1\% в 2018 г., 17,9\% в 2019 г. до 27\% в 2020 г. Как видно, в структуре потребления этих препаратов доля дабигатрана незначительна (см. табл. 1), основная доля реализации принадлежит представителям прямых ингибиторов фактора Хa: ривароксабану и апиксабану (ATX-подгруппа B01AF), а лидирует апиксабан. В период с 2019 по 2020 г. доля этой подгруппы возросла с 14,7 до 24,0\% (см. табл. 1). Объемы продаж в натуральном выражении для апиксабана выросли на 227\%, ривароксабана - на $168 \%$. Меньший спрос на ривароксабан, очевидно, обусловлен большей стоимостью эквивалентной дозы (табл. 2). Доля конкурирующих оральных антикоагулянтов - 
Таблица 2. Средняя стоимость одной суточной дозы антиагрегантных и антикоагулянтных ЛП в 2019-2020 гг.

Table 2. Average cost per daily dose of antiaggregant and anticoagulant drugs in 2019-2020

\begin{tabular}{|c|c|c|}
\hline \multirow[t]{2}{*}{ Группа/Мнн } & \multicolumn{2}{|c|}{$\begin{array}{c}\text { Медиана (минимум-максимум) стоимости } \\
\text { 1DDD, руб. }\end{array}$} \\
\hline & 2019 г. & 2020 г. \\
\hline $\begin{array}{l}\text { В01АА «Антагони- } \\
\text { сты витамина К» }\end{array}$ & $6,25(2,46-37,33)$ & $5,04[3,08-20,92]$ \\
\hline Фениндион & $11,06(11,06-11,06)$ & $20,92(20,92-20,92)$ \\
\hline Варфарин & $4,16(2,46-6,88)$ & $4,81(3,08-5,70)$ \\
\hline Аценокумарол & $37,33(37,33-37,33)$ & - \\
\hline $\begin{array}{l}\text { В01АВ «Гепарин и } \\
\text { его производные» }\end{array}$ & $210,23(45,09-279,65)$ & $234,51[13,42-813,72]$ \\
\hline Гепарин натрия & $226,26(217,19-274,50)$ & $283,90(245,01-813,72)$ \\
\hline Далтепарин натрия & $159,69(159,69-159,69)$ & $279,06(216,10-342,03)$ \\
\hline $\begin{array}{l}\text { Эноксапарин } \\
\text { натрия }\end{array}$ & $133,30[(45,09-203,28]$ & $121,70(13,42-201,56)$ \\
\hline $\begin{array}{l}\text { Надропарин } \\
\text { кальция }\end{array}$ & $279,65(237,39-279,65)$ & $284,71(267,03-319,77)$ \\
\hline Парнапарин натрия & $248,34(248,34-248,34)$ & $238,36(188,94-246,94)$ \\
\hline Сулодексид & $129,91(104,63-155,183)$ & $145,00(115,63-270,23)$ \\
\hline $\begin{array}{l}\text { В01АС «Ингибиторы } \\
\text { агрегации тромбо- } \\
\text { цитов (исключая } \\
\text { гепарин)» }\end{array}$ & $15,44(0,71-204,59)$ & $15,62(0,77-208,97)$ \\
\hline Клопидогрел & $16,60(9,85-48,57)$ & $18,10(9,97-49,31)$ \\
\hline ACK & $1,69(0,71-5,42)$ & $1,69(0,77-5,35)$ \\
\hline Дипиридамол & $69,33(50,69-120,48)$ & $71,49(57,92-165,37)$ \\
\hline Прасугрел & $144,10(144,10-144,10)$ & $188,94(188,94-188,94)$ \\
\hline Цилостазол & $101,17(87,39-175,58]$ & $102,96(89,71-174,52)$ \\
\hline Тикагрелор & $197,41(192,50-204,59)$ & $202,92(186,83-208,97)$ \\
\hline $\begin{array}{l}\text { В01АЕ «Прямые } \\
\text { ингибиторы } \\
\text { тромбина» }\end{array}$ & $162,00(125,27-303,03)$ & $166,15(133,25-209,57)$ \\
\hline $\begin{array}{l}\text { Дабигатрана } \\
\text { этексилат }\end{array}$ & $162,00(125,27-303,03)$ & $166,15(133,25-209,57)$ \\
\hline $\begin{array}{l}\text { B01AF «Прямые } \\
\text { ингибиторы } \\
\text { фактора Ха» }\end{array}$ & $165,81(102,36-298,76)$ & $186,27(103,92-626,90)$ \\
\hline Ривароксабан & $165,81(119,56-298,76)$ & $186,27(127,55-626,90)$ \\
\hline Апиксабан & $153,79(102,36-205,30)$ & $157,50(103,92-210,00)$ \\
\hline $\begin{array}{l}\text { B01AX «Прочие } \\
\text { антикоагулянты» }\end{array}$ & - & $837,22(837,22-837,22)$ \\
\hline $\begin{array}{l}\text { Фондапаринукс } \\
\text { натрия }\end{array}$ & - & $837,22(837,22-837,22)$ \\
\hline
\end{tabular}

кумариновых производных - антагонистов витамина К, продажи которых традиционно обеспечены варфарином от 77,3\% в 2015 г. до 91,7\% в 2020 г., закономерно уменьшалась в исследуемый период (см. табл. 1).

Повышение объемов продаж антикоагулянтов особенно заметно в 2020 г. (см. табл. 1), что обусловлено влиянием распро-

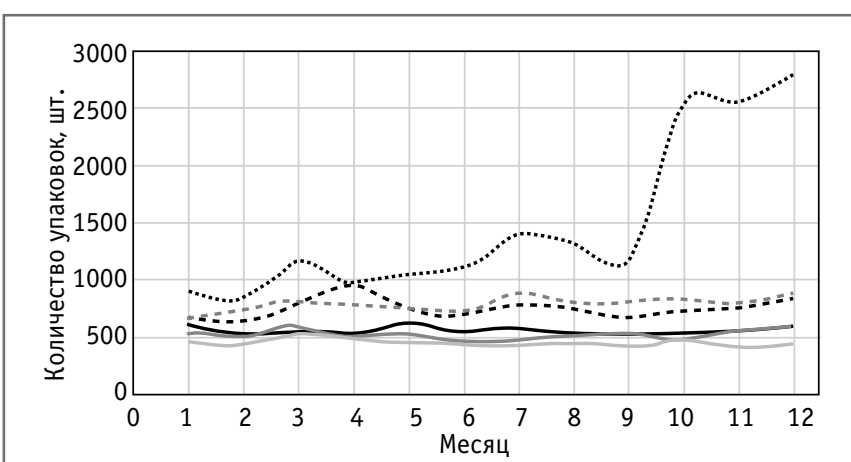

—2015 г. — 2016 г. —2017 г. - --2018 г. =- 2019 г. ......2020 г.

Рис. 5. Динамика изменения спроса на антиагрегантные и антикоагулянтные ЛП в 2015-2020 гг.

Fig. 5. Dynamics of demand for antiaggregant and anticoagulant drugs in 2015-2020.

странения новой коронавирусной инфекции, так как ривароксабан, апиксабан и низкомолекулярные гепарины включены в методические рекомендации Минздрава России и международные рекомендации для профилактики тромбоза глубоких вен и тромбоэмболии легочной артерии у пациентов, госпитализированных с COVID-19, а также после выписки при сохраняющемся повышенном риске венозных тромбоэмболических осложнений и низком риске кровотечений [13].

Средняя доля оригинальных ЛП в общем количестве отпущенных антикоагулянтных и антиагрегантных ЛП в 20152020 гг. составила 21,6\% (диапазон - от 15,7\% в 2015 г. до 34,2\% в 2020 г.).

При анализе реализации ЛП по месяцам отмечается существенный рост потребления антитромботических препаратов в конце 2020 г. (октябрь-декабрь), превышающий соответствующие значения в 2015-2019 гг., что совпадает с ростом заболеваемости COVID-19 в Самарской области (рис. 5).

В 2020 г. медианная стоимость 1 DDD при лечении антикоагулянтными и антиагрегантными ЛП составляла 57,92 руб. и варьировала в пределах от 0,77 (АСК) до 837,2 руб. (фондапаринукс натрия); см. табл. 2. В 2019 г. медианная стоимость составляла 39,19 руб., диапазон варьирования - от 0,71 (АСК) до 303,0 руб. (дабигатрана этексилат). Препараты фондапаринукса натрия в аптечной сети в 2019 г. не были представлены. Стоимость лечения оригинальными препаратами достоверно превышала стоимость лечения воспроизведенными препаратами.

Как видно из табл. 2, медианы стоимости 1 DDD для большинства рассматриваемых групп антитромбоцитарных ЛП не превышали 200 руб., при этом наименьшие медианы стоимости имели антагонисты витамина $\mathrm{K}$ и ингибиторы агрегации тромбоцитов (см. табл. 2). Наибольшая стоимость 1 DDD отмечена для ЛП АTX-подгрупп «Гепарин и его производные» и «Прочие антикоагулянты». При анализе отдельных МНН выявлено, что наибольшую стоимость 1 DDD имели ЛП с действующими веществами фондапаринукс натрия, надропарин кальция, парнапарин натрия (см. табл. 2). Определено, что по отношению к соответствующему значению в 2019 г. стоимость 1 DDD в 2020 г. в среднем возросла на 15,9\%.

\section{Заключение}

Доля основных ССП в натуральном выражении, реализуемая населению через сегмент аптечной сети, незначительна и не соответствует распространенности сердечно-сосудистой патологии, требующей долговременной фармакотерапии. В период распро- 
странения COVID-19 она уменьшилась с 5,2 (2015-2016 гг.) до 3\% в 2020 г. Наибольший объем продаж относится к препаратам группы ИАПФ (28\%) и $\beta$-адреноблокаторов (23,5\%). ФК гипотензивных препаратов составляют лишь $13 \%$ объема реализованных основных ССП, преимущественно представлены двухкомпонентными препаратами, доля трехкомпонентных ФК несущественна $-0,7 \%$.

Доля статинов в общем объеме продаж основных ССП составляет 7,6\%, что не соответствует их роли как наиболее эффективных препаратов в первичной и вторичной кардиопревенции.

Доля антитромботических препаратов в общем объеме продаж в натуральном выражении в 2015-2019 гг. составляет 0,45\%. В абсолютном выражении продажи антикоагулянтов и дезагрегантов возросли в 2018-2020 гг., что сопровождалось увеличением стоимости 1 DDD в среднем на 15\%. В течение всего временного промежутка максимальная доля 00Р антитромботических ЛП приходится на ATX-подгруппу B01AC «Ингибиторы агрегации тромбоцитов».

Среди дезагрегантов наиболее часто реализуется АСК $(66,6 \%)$ в виде генерических препаратов, клопидогрел (21,6\%), дипиридамол (10,2\%). Доля дезагрегантов в объемах продаж снизилась с 74,8 до 57,6\% за счет препаратов АСК. Наиболее значительно в 2020 г. выросло потребление дипиридамола - до $16,6 \%$ - в связи с включением препарата в протоколы ведения пациентов c COVID-19. Доля продаж новых дезагрегантов - прасугрела и тикагрелора - незначительна.

Среди антикоагулянтов доля новых оральных препаратов характеризуется поступательным увеличением с 7,8\% в 2015 г. до 27\% в 2020 г. Впервые за исследуемый период доля гепарина и его производных в 2020 г. была ниже реализованного коли- чества упаковок оральных антикоагулянтов - 16,9\%. В период пандемии COVID-19 наиболее востребованной является группа блокаторов Ха фактора с преобладанием апиксабана (63,8\%), что может объясняться более низкой стоимостью (на 16\%) 1 DDD в сравнении с ривароксабаном.

Раскрытие информации. Авторы декларируют отсутствие явных и потенциальных конфликтов интересов, связанных с публикацией настоящей статьи.

Disclosure. The authors declare that they have no competing interests.

Вклад авторов. Авторы декларируют соответствие своего авторства международным критериям ICMJE. Все авторы в равной степени участвовали в подготовке публикации: разработка концепции статьи, получение и анализ фактических данных, написание и редактирование текста статьи, проверка и утверждение текста статьи.

Authors' contribution. The authors declare the compliance of their authorship according to the international ICMJE criteria. All authors made a substantial contribution to the conception of the work, acquisition, analysis, interpretation of data for the work, drafting and revising the work, final approval of the version to be published and agree to be accountable for all aspects of the work.

Источник финансирования. Авторы декларируют отсутствие внешнего финансирования для проведения исследования и публикации статьи.

Funding source. The authors declare that there is no external funding for the exploration and analysis work.

\section{Информация об авторах / Information about the authors}

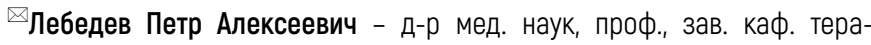
пии Института профессионального образования ФГБОУ ВО СамГМУ. E-mail: palebedev@yahoo.com; ORCID: 0000-0003-1404-7099

Петрухина Ирина Константиновна - д-р фармацевт. наук, доц., зам. дир., зав. каф. управления и экономики фармации Института фармации ФГБОУ BO СамГMY. ORCID: 0000-0001-6207-5575

Рязанова Татьяна Константиновна - канд. мед. наук, канд. фармацевт. наук, доц. каф. управления и экономики фармации ФГБОУ ВО СамГМу. ORCID: 0000-0002-4581-8610

Блинкова Полина Романовна - аспирант каф. управления и экономики фармации ФГБОУ ВО СамГМУ. ORCID: 0000-0002-8604-0729

Паранина Елена Владимировна - канд. мед. наук, доц. каф. терапии Института профессионального образования ФГБОУ ВО СамГМУ. ORCID: 0000-0001-7021-4061 $\triangle$ Petr A. Lebedev - D. Sci. (Med.), Prof., Samara State Medical University. E-mail: palebedev@yahoo.com; ORCID: 0000-0003-1404-7099

Irina K. Petrukhina - D. Sci. (Pharmaceut.), Assoc. Prof., Samara State Medical University. ORCID: 0000-0001-6207-5575

Tatyana K. Ryazanova - Cand. Sci. (Med.), Cand. Sci. (Pharmaceut.), Samara State Medical University. ORCID: 0000-0002-4581-8610

Polina R. Blinkova - Graduate Student, Samara State Medical University. ORCID: 0000-0002-8604-0729

Elena V. Paranina - Cand. Sci. (Med.), Samara State Medical University. ORCID: 0000-0001-7021-4061

\section{Литература/References}

1. Guan WJ, Liang WH, He JX, Zhong NS. Cardiovascular comorbidity and its impact on patients with COVID-19. Eur Respir J. 2020;55(6):2001227. DOI:10.1183/13993003.01227-2020

2. Potere $N$, Valeriani $E_{1}$ Candeloro $M$, et al. Acute complications and mortality in hospitalized patients with coronavirus disease 2019: a systematic review and meta-analysis. Crit Care. 2020;24(1):389. D0I:10.1186/s13054-020-03022-1

3. Болевич С.Б., Болевич С.С. Комплексный механизм развития COVID-19. Сеченовский вестник. 2020;11(2):50-61 [Bolevich SB, Bolevich SS. Complex mechanism of COVID-19 development. 
Sechenov Medical Journal. 2020;11(2):50-61 (in Russian)]. DOI:10.47093/2218-7332.2020.11.2.50-61

4. Responding to noncommunicable diseases during and beyond the COVID-19 pandemic. Jeneva 2020 (WHO/2019-nCoV/Noncommunicable_ diseases/Policy_brief/2020).

5. Monaco A, Blanco AC, Cobain $M$, et al. The role of collaborative multistakeholder partnerships in reshaping the health management of patients with noncommunicable diseases during and after the COVID 19 pandemic. Aging Clin Exp Res. 2021;33:2899-907. DOI:10.1007/s40520-021-01922-y

6. Леонова М.В., Штейнберг Л.Л., Белоусов Ю.Б., и др. Результаты фармакоэпидемиологического исследования артериальной гипертонии Пифагор IV: приверженность врачей. Рос. кардиол. журн. 2015;(1117):59-66 [Leonova MV, Steinberg LL, Belousov YuB, et al. Results of pharmacoepidemiologic study of arterial hypertension Pifagor IV: Physicians compliance. Russian Journal of Cardiology. 2015;(1):59-66 (in Russian)]. DOl:10.15829/1560-4071-2015-1-59-66

7. Фармацевтический рынок России 2020. Режим доступа: https://dsm. ru/docs/analytics/2020_Report_rus.pdf. Ссылка активна на 05.12.2021 [Pharmaceutical Market in Russia 2020. Available at: https://dsm.ru/ docs/analytics/2020_Report_rus.pdf. Accessed: 05.12 .2021 (in Russian)].

8. The top 300 drugs of 2021 provided by the ClinCalc drugstats Database. Available at: https://clincalc.com/DrugStats/Top300Drugs.aspx. Accessed: 05.12.2021.

9. Roth GA, Mensah GA, Johnson CO, et al. Global Burden of Cardiovascular Diseases and Risk Factors, 1990-2019: Update From the GBD 2019 Study. J Am Coll Cardiol. 2020;76(25):2982-3021. D0I:10.1016/j.jacc.2020.11.010
10. Whelton PK, Carey RM, Aronow WS, et al. 2017 ACC/AHA/AAPA/ABC/ACPM/ AGS/APhA/ASH/ASPC/NMA/PCNA guideline for the prevention, detection, evaluation, and management of high blood pressure in adults: executive summary: a report of the American College of Cardiology/American heart association task force on clinical practice guidelines. J Am Soc Hypertens. 2018;12(8):579.e1-73. D0I:10.1016/j.jash.2018.06.010

11. Бурашникова И.С., Цветов В.М., Мирзаев К.Б., Сычев Д.А. Возможность и перспективы применения препарата дипиридамол у пациентов с COVID-19. Качественная клиническая практика. 2020;4S:92-5 [Burashnikova IS, Tsvetov VM, Mirzaev KB, Sychev DA. Current and future use of dipyridamole in patients with COVID-19. Good Clinical Practice. 2020:4S:92-5 (in Russian)]. DOI:10.37489/2588-0519-2020-S4-92-95

12. Куртов И.В., Берман Ю.О., Никулина Н.А. Возможность неспецифической первичной профилактики новой коронавирусной инфекции COVID-19 у медицинских работников с применением дипиридамола. Тромбоз, гемостаз и реология. 2020;4 [Kurtov IV, Berman YO, Nikulina NA, et al. The opportunity of dipyridamole using for nonspecific primary prophylaxis against the COVID-19 infection in healthcare staff. Tromboz, gemostaz i reologiya. 2020;4 (in Russian)]. DOl:10.25555/THR.2020.4.0947

13. Профилактика, диагностика и лечение новой коронавирусной инфекции (COVID-19). Временные методические рекомендации. Краткая версия. Режим доступа: https://covid19.rosminzdrav.ru/wpcontent/uploads/2021/10/short_bmp_13-1.pdf. Ссылка активна на 05.12.2021 [Prevention, diagnosis and treatment of new coronavirus infection (COVID-19). Interim guidelines. Short version. Available at: https://covid19.rosminzdrav.ru/wp-content/uploads/2021/10/short_ bmp_13-1.pdf. Accessed: 05.12 .2021 (in Russian)].

Статья поступила в редакцию / The article received: 12.11.2021

Статья принята к печати / The article approved for publication: 24.12.2021

Статья опубликована / Article published: 30.12.2021

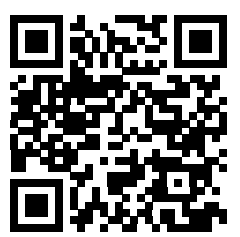

OMNIDOCTOR.RU 